\title{
La importancia de la homeostasis en la salud oral y sistémica.
}

\author{
The importance of homeostasis in oral and systemic health.
}

\author{
Abner Escobedo Escobedo*
}

\section{RESUMEN}

La homeostasis oral está regida por varias condiciones en la cavidad bucal, como la saliva, que está compuesta por diversas sustancias benéficas, y por la microbiota, que es un reservorio de microorganismos, y cuando estos se modifican se altera la homeostasis oral y se genera una disbiosis que puede conducir a enfermedades bucales como gingivitis, periodontitis y/o caries; también puede favorecer el desarrollo de enfermedades sistémicas ocasionadas por hongos, bacterias y virus como el SARS-CoV-2.

Palabras clave: Homeostasis, saliva, microbioma, microbiota, disbiosis, SARS-CoV-2.

\section{ABSTRACT}

Oral homeostasis is governed by various conditions in the oral cavity such as saliva, which is composed of various beneficial substances, and by the microbiota, which is a reservoir of microorganisms, and when these are modified, homeostasis of the oral cavity is altered and dysbiosis is generated that They can lead to oral diseases such as gingivitis, periodontitis and/or caries and can also favor the development of systematic diseases caused by fungi, bacteria and viruses, like SARS-CoV-2.

Keywords: Homeostasis, saliva, microbiome, microbiota, dysbiosis, SARS-CoV-2.

\section{INTRODUCCIÓN}

$\mathrm{L}$ a homeostasis es un conjunto de fenómenos de autorregulación, conducentes al mantenimiento de una constancia relativa en la composición y las propiedades del medio interno de un organismo. ${ }^{1}$ El microbioma y el genoma de la microbiota oral son un conjunto de genes que interactúan para codificar diversas acciones para el propio genoma humano. ${ }^{2}$ Además, el microbioma suele presentar mayor cantidad de genes codificados que el propio genoma humano; el mejor ejemplo es que el genoma humano codifica aproximadamente 23,000 genes mientras que su microbioma codifica alrededor de tres millones de genes. La homeostasis también define el número total de microorganismos que componen el microbioma y su material genético, lo que no hay que confundir con la microbiota residente en cada sitio específico del organismo. ${ }^{3}$ La disbiosis, también llamada disbacteriosis, es el desbalance del equilibrio microbiano de la microbiota normal, debido a cambios cuantitativos o cualitativos. La homeostasia depende de un estado de eubiosis cuando la microbiota, teóricamente «normal» y «equilibrada», cumple presumiblemente todos los requisitos para que nos podamos beneficiar de sus efectos sobre la salud a nivel metabólico, inmunitario, neuronal y de barrera protectora, propios de un individuo sano (Figuras 1 a 3).

La saliva es un componente de la cavidad bucal con secreción de 1 a 1.5 litros diarios puede ser serosa, mucosa o mixta, secretadas por las glándulas parótidas, sublingual y submaxilar. Y además contiene electrolitos como fosfatos, sodio, potasio, magnesio, calcio, bicarbonatos, enzimas, proteínas, mucina e inmunoglobulinas. ${ }^{1}$ Todos estos compuestos nos mantienen la homeostasis bucal; también está la microbiota, que son microorganismos ${ }^{3}$ presentes en saliva que pueden verse alterados cuando se modifica la homeostasis bucal por alteraciones en el

\footnotetext{
* Egresado de la Facultad de Estomatología de la UASLP. Miembro y certificado por la ADM. Certificate by Ada Dental Hygiene.

Recibido: 27 de mayo de 2020. Aceptado: 30 de enero de 2021.

Citar como: Escobedo EA. La importancia de la homeostasis en la salud oral y sistémica. Rev ADM. 2021; 78 (1): 48-50. https://dx.doi.org/10.35366/98387
}

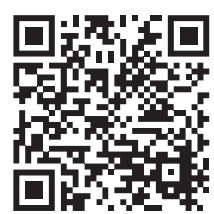


medio ambiente bucal, disminución en el flujo salival, el cambio de $\mathrm{pH}$ salival de neutro a ácido y falta de higiene bucal, lo cual favorece el crecimiento de bacterias patógenas que pueden ocasionar enfermedades en mucosas, encías y dientes. ${ }^{4}$ También la cavidad bucal es la vía de entrada y primer barrera de difusión de microorganismos hacia las amígdalas, faringe, laringe y esófago, por lo que es importante reducir la carga de microbiota anormal y patógena que podría favorecer el desarrollo de enfermedades bucodentales y sistémicas.

En ediciones pasadas ${ }^{5,6}$ se abordan la susceptibilidad y vulnerabilidad de personas que, por actividad física y condición sistémica, están propensas a desarrollar lesiones y/o enfermedades por el desequilibrio de la homeostasis

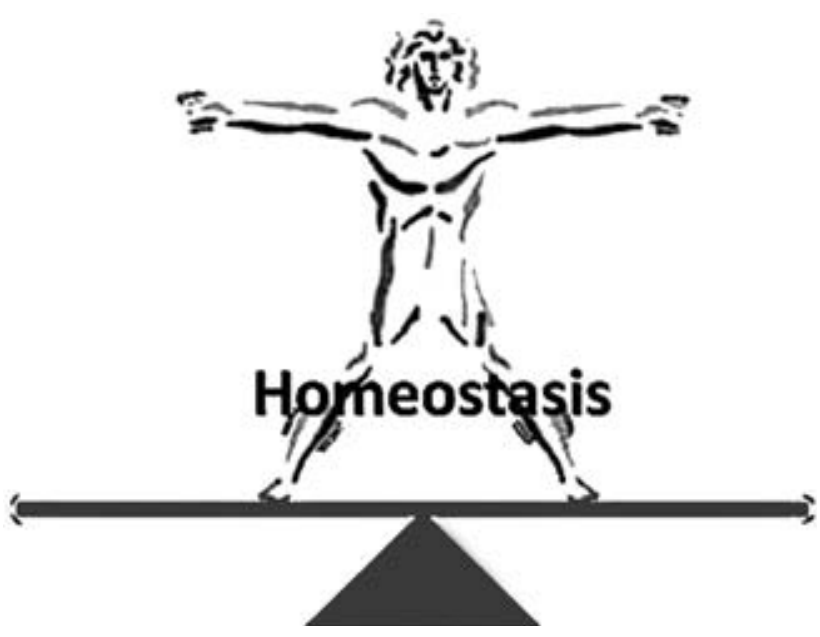

Figura 1: Homeostasis.

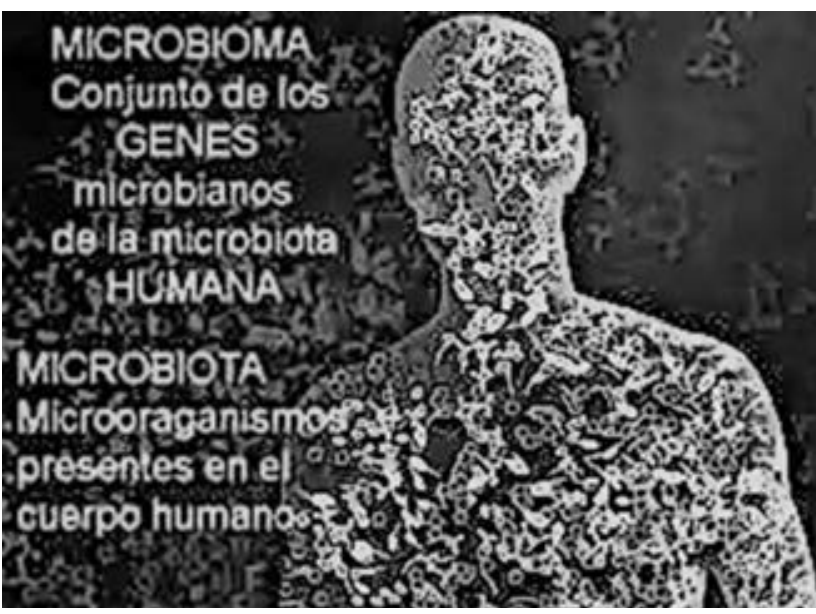

Figura 2: Microbioma-microbiota.

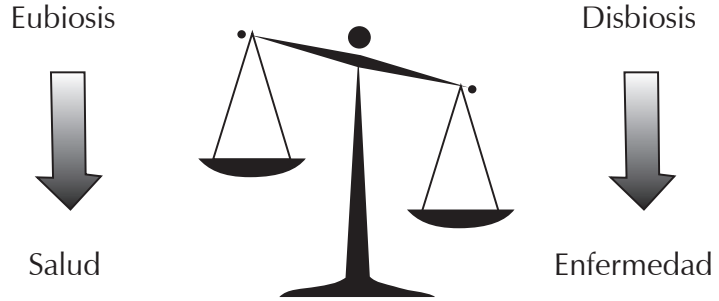

Figura 3: Eubiosis-disbiosis.

Origen animal de los coronavirus humanos

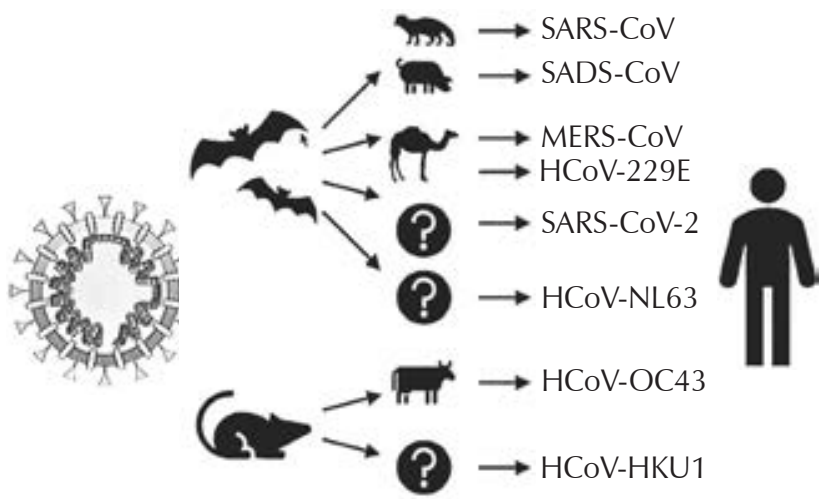

Figura 4: Coronavirus de origen animal.

oral y sistémica que tienen alterada. Estos dos grupos de pacientes, en los extremos cada uno: el que práctica deporte amateur o profesional; y el inmunodeprimido por estar en protocolo para trasplante de órgano. El paciente que practica deporte está en riesgo de desarrollar lesiones bucodentales por las fuerzas intrínsecas que se generan por la contractura muscular no sólo de los músculos que se ejercitan durante la práctica deportiva, sino también de los músculos faciales, periorales y masticatorios que generan sobrecargas en los dientes y articulación temporomandibular, sumado a la xerostomía por la deshidratación que desarrollan ante la demanda y el desgaste físico durante la práctica deportiva. Y en el otro grupo en protocolo para trasplante de órgano, padecen inmudepresión que los vuelve susceptibles a desarrollar infecciones por microorganismos oportunistas, tanto local en cavidad oral como sistémicamente en otros órganos. Ambos grupos de casos tienen alterada la homeostasis por diferentes razones, unos por la actividad deportiva y los otros por su condición sistémica, pero ambos vulnerables y susceptibles a desarrollar lesiones y enfermedades bucodentales y sistémicas. Por esto debemos dar atención específica 
a cada caso, dando las recomendaciones adecuadas de acuerdo con su nivel de vulnerabilidad y susceptibilidad, ${ }^{7}$ para que así mantengan su homeostasis oral de acuerdo con su edad, sexo, actividades, alteraciones sistémicas, y antecedentes médico-familiares de salud en general, ya que con la homeostasis oral y sistémica alterada son vulnerables a desarrollar enfermedades ocasionadas por virus como VIH, hepatitis y herpes, que están presentes en cavidad oral aunado al SARS-CoV-2.

Los virus han estado presentes desde el inicio de la humanidad, pero no pueden vivir por sí mismos, y requieren de una célula para replicarse. Existen gran variedad de virus que pueden replicarse en cualquier grupo biológico, procariontes, protistas, hongos, plantas y animales (Figura 4).

En los últimos 25 años, hemos tenido un embate de varias enfermedades causadas por virus y que han afectado a grandes grupos de poblaciones; ahora se produjo una pandemia por el virus SARS-CoV-2 que es de la familia de los coronavirus y está presente en animales, en los cuales no ocasiona enfermedad, pero cuando ha pasado al ser humano sí ha llegado a ocasionar graves enfermedades como el MERS, el SARS, $\mathrm{CoV}^{8}$ y la que ahora está presente, COVID-19 (Figura 5).

Así que, hoy más que nunca, debemos tener y hacer una evaluación más detallada de cada caso que atendemos día a día para ayudarles con recomendaciones específicas para mantener la homeostasis oral y así reducir el riesgo de desarrollar enfermedades bucodentales y sistémicas. Las recomendaciones a cada paciente tienen el objetivo de cuidar la microbiota normal benéfica y reducir la carga microbiana anormal y patógena de bacterias, hongos y virus. En el caso particular del SARS-CoV-2 se ha estudiado que, para reducir la carga viral que se acumula en boca y garganta, se deben hacer colutorios y gargarismos con agua oxigenada al $1 \%$ o iodopovidona $0.2 \%$ por un minuto además de la higiene oral previa con el uso de

Familia de coronavirus humanos
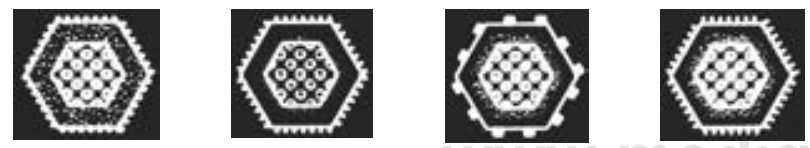

HCoV-OC43

HCoV-229E

HCoV-NL63

HCOV-HKU1

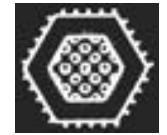

MERS-CoV

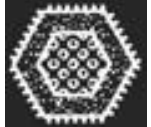

SARS-CoV

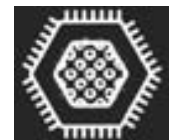

SARS-CoV-2
Figura 5: Familia del coronavirus. hilo dental, cepillado dental, limpia lengua, parte interna de carrillos y paladar. ${ }^{9}$ Además de prepararnos en la parte de tratamientos de cirugía, operatoria y de rehabilitación dental, debemos ver al paciente con una visión amplia sistémica para evaluar sus riesgos de susceptibilidad y vulnerabilidad ${ }^{7}$ que lo condujeron a alterar su homoestasis oral y desarrollar los padecimientos donde nosotros intervenimos, para realizar el tratamiento más adecuado y oportuno, además hacer recomendaciones para que cada paciente mejore sus hábitos que lo conduzcan a restablecer la homeostasis y salud oral.

- Hipócrates el Médico Griego dijo hace más de 2400 años; «Antes de curar a alguien, pregúntale si está dispuesto a renunciar a las cosas que lo enfermaron».

\section{REFERENCIAS}

1. Lamy E, Capela-Silva F. Research on saliva secretion and composition. BioMed Research International. 2018; Article ID 7406312. Available in: https://doi.org/10.1155/2018/7406312.

2. Zerón A. Genoma, microbioma y epigenoma humano. Una visión contemporánea de la triada ecológica. Rev ADM. 2014; 71 (4): 162-170.

3. Dyszkiewicz-Konwinska $M$, Nawrocki MJ, Huang $Y$, Bryja A, Celichowski P, Jankowski $M$ et al. New gene markers for metabolic processes and homeostasis in porcine buccal pouch mucosa during cells long term-cultivation. A primary culture approach. Int J Mol Sci. 2018; 19 (4): 1027. doi: 10.3390/ijms19041027. www.mdpi. com/journal/ijms.

4. Sharma N, Bhatia S, Singh SA, Batra N. Oral microbiome and health. AIMS Microbiol. 2018; 4 (1): 42-66. doi: 10.3934/ microbiol.2018.1.42.

5. Escobedo EA, Ramos LJD, Tejeda NFJ. Atención estomatológica a pacientes en protocolo para trasplante de órgano. Rev ADM. 2019; 76 (2): 85-90.

6. Escobedo EA Odontología deportiva y prevención de trauma dentoalveolar. Rev ADM 2019,76(6)328-331.

7. Iturbe M, Zerón A. Nueva visión genómica de las enfermedades periodontales. Rev Mex Periodontol. 2015; 6 (2): 74-76.

8. Zhou P, Yang XL, Wang XG, Hu B, Zhang L, Zhang W et al. A pneumonia outbreak associated with anew coronavirus of probable bat origin. Available in: https://doi.org/10.1038/s41586-020-2012-7.

9. Eggers $M$, Koburger-Janssen T, Eickmann $M$, Zorn J. In vitro bactericidal and virucidal efficacyof povidone-iodine gargle/ mouthwash against respiratory and oral tract pathogens. Infect Dis Ther. 2018; 7 (2): 249-259. Available in: https://doi.org/10.1007/ s40121-018-0200-7.

\section{Correspondencia: \\ Dr. Abner Escobedo Escobedo \\ E-mail.abnerescobedo@aol.com}

Conflicto de intereses: El autor declara no tener ningún conflicto de intereses. 